\title{
Integrated Plastic Management System Within an Agricultural Enterprise Analysis of actual context, system model and simulation
}

\begin{abstract}
VICTOR TITA ${ }^{1}$, DORINA-NICOLETA MOCUTA², ADRIAN TUREK-RAHOVEANU², DORU ANASTASIU PO PESCU³, NICOLAE BOLD ${ }^{3 *}$ 'University of Agricultural Sciences and Veterinary Medicine Bucharest, Faculty of Management and Rural Development, Slatina Branch, 150 Streharei Str., 230088, Slatina, Romania

ZUniversity of Agricultural Sciences and Veterinary Medicine Bucharest, Faculty of Management and Rural Development, 59 Marasti Blvd., 011464, Bucharest, Romania

3University of Pitesti, Faculty of Sciences, Physics Education and Computer Science, 1 Targul din Vale, 110040, Pitesti, Romania

The enterprise has an intricate and elaborate system of relationships between the departments, functioning closely as a cell within an organism, with its defined role within the market. In the complex context of actual economic system, resources are limited and enterprises seek for efficiency in order to reduce costs. In this paper we present the development of a solution for the optimization of an agricultural enterprise related to the plastic-based materials usage in the agricultural processes. In this matter, the experimental part consists in the creation of a model of a plastic management system using methodologies from the literature (e. g., System Dynamics or SD etc.) and its simulation with specific tools used traditionally. Besides the experimental part, we will make a short analysis regarding the structural and economic issues regarding plastics used in agriculture and some considerations regarding the bioplastic material that can be obtained from different types of agricultural waste.
\end{abstract}

Keywords: waste management, plastic, agriculture, optimality

Due to their maneuverability and their low cost, plastics are used widely in agriculture, especially in the form of foils, used for packing and cover, or as pipes, used for irrigations. Some of the most usual directions of usage of plastics are shown in Table 1 [1]. However, one of the most disruptive effect of plastic materials in agriculture is the pollution of the soil, brought by the nature of the material and the bad manipulation of foils and pipes [2]. The bad effects of plastic can be, however, limited by using materials with the same proprieties which affect less the soil. In this direction, research has been made for the development of bioplastics.

The main materials used in agriculture are LDPE (LowDensity Polyethylene), EVA (Ethylene-Vinyl Acetate), PP (Polyethylene), PVC (Polyvinyl Chloride) and HDPE (HighDensity Polyethylene). Due to their proprieties, such as strength and possibility to be foiled, these materials are common in the agriculture of today. Some of the proprieties of these materials are shown in table 2.
These plastic materials have the unique capability to reduce cost implications and to increase the optimal character of the enterprise economy [3], as well as growing the final value of the product. This consists in the importance of the plastic material management within an enterprise. In order to increase the optimality, one of the best modalities of determining the importance of system components and measuring this importance scientifically is testing the model of the system. Some of the most used methods are System Dynamics, Business Process Modelling Notation and methods based on model checking or system engineering.

\section{Experimental part}

The core of the research consists in developing a model close to reality using specific methodologies [4] related to model construction and its simulation based on key parameters. These two processes lead the reader of the model to conclusions related to the usage of plastic materials within an agricultural enterprise. The main

\begin{tabular}{|l|l|}
\hline Application & Plastic types used \\
\hline Mulching & LLDPE, LDPE, EVA, PVC \\
\hline Low tunnels & LDPE, EVA, PVC \\
\hline Direct covers & LLDPE, LDPE, EVA, PP \\
\hline Tunnels and parallels & LDPE, EVA, PVC \\
\hline Greenhouses & LDPE, EVA, PVC, PC, PMMA \\
\hline Lightweight structures & LDPE, EVA, PVC \\
\hline Silage & LLDPE, LDPE, EVA, PVC \\
\hline Nets & LLDPE, LDPE, EVA, HDPE, PVC, PP \\
\hline Water reservoirs & LLDPE, LDPE, EVA, HDPE, PVC \\
\hline Hydroponics & LLDPE, LDPE, EVA \\
\hline Windbreakers & LLDPE, LDPE, HDPE, PP \\
\hline Irigation and drainage pipes & LLDPE, LDPE, EVA, HDPE, PVC, PP \\
\hline Containers & LLDPE, LDPE, HDPE, PP \\
\hline Agricultural twine & PP \\
\hline
\end{tabular}

Table 1

PLASTICS USED IN AGRICULTURE

*email: bold_nicolae@yahoo.com / (+40) 737989420 


\begin{tabular}{|c|c|c|c|c|c|c|}
\hline & Tensile Strength & $\begin{array}{l}\text { Flexural } \\
\text { Modulus of } \\
\text { Elasticity }\end{array}$ & $\begin{array}{l}\text { Izod Impact } \\
\text { (notched) }\end{array}$ & $\begin{array}{l}\text { Heat Deflection } \\
\text { Temperature }\end{array}$ & $\begin{array}{c}\text { Water } \\
\text { Absorption }\end{array}$ & Table? \\
\hline & $23^{\circ} \mathrm{C}$ & $23^{\circ} \mathrm{C}$ & $23^{\circ} \mathrm{C}$ & $66 p s i / 264 p s i$ & $\begin{array}{c}\text { Immersion } 24 \\
\text { hours }\end{array}$ & MAIN CHARACTERISTICS OF \\
\hline Units & $M P a$ & $M P a$ & $f t-l b s / i n$ & ${ }^{\circ} \mathrm{C}$ & $\%$ & \\
\hline ASM test & D638 & D790 & $\mathrm{D} 256$ & D648 & D570 & \\
\hline EVA & 26.54 & 17.03 & - & - & - & \\
\hline LDPE & 9.65 & 206.84 & no break & 50 & 0.10 & \\
\hline $\mathrm{PP}$ & 37.23 & 1551.32 & 1.2 & $99-$ & slight & \\
\hline PVC & 7.500 & 3316.38 & 1.0 & -70 & 0.06 & \\
\hline HDPE & 51.71 & 1378.95 & - & $78-$ & 0.10 & \\
\hline LLDPE & $7.93-45.51$ & $2.40-110$ & $5.00-8.01$ & - & 0.01 & \\
\hline
\end{tabular}

advantage of using an SD approach is the graphical representation of the system structure and behavior, which can lead to significant conclusions related to the development of the system in the reality. Thus, the final result is a stock-and-flow diagram or a casual-loop diagram. In the model, the enterprise is considered to be a farm that produces crops and vegetables.

The steps of the methodology followed to create and simulate the model presented in this paper with respect to the literature [5] approaches are:

1.The conceptualization of the model, which comprises the theoretical definition of the model and the work made in order to properly model the system in a mathematical language. This step had four sub-steps:

a.The definition of the modeling activity purpose. In our case, the purpose of the model is to describe an integrated plastic management system within an agricultural enterprise, in order to optimize the economic activity [6], the protection of the environment [7] and to emphasize the importance of the plastic materials within the enterprise economy.

b.The determination of the boundaries and the key variables selection. The list of the values chosen to be distinctive for the described model are shown in table 2.
Also, a classification will be made based on the stock or flow type and endogenous or exogenous character.

c.The reference modes. This step consists in the representation of the behavior of the variables selected at the previous step based on real-time statistics, if the history of the parameters can be obtained. The major challenge at this step is the choice of the time span, which will also consist in the time span of the model. For our model, the time span was chosen to be one year.

d.Building the mechanisms and feedback loops. The graphical representation of the model is represented in figure 1.

2.The formulation of the model, which consists in the determination of the equations that link the key variables and add the dynamic character to the model. These equations will help further at the simulation phase. In our model, the equations that model the links between the variables are those related to:

-the calculation of the production cost

$$
c=c v+w v+f v+c h v+o v+a v+s v+p v+h w v
$$

-the calculation of the plastics usage value $p v=g f v+n v+p p v+m v+t v+d c v+w f v-b p v$

\begin{tabular}{|c|c|c|c|c|}
\hline Variable & $\begin{array}{c}\text { Stock/flow / } \\
\text { Auxiliary }\end{array}$ & $\begin{array}{c}\text { Endogenous (I) / } \\
\text { exogenous (O) }\end{array}$ & Notation & Unit \\
\hline Production cost & Flow & I & $\mathrm{c}$ & lei \\
\hline Production value & Stock & $\mathrm{I}$ & $\mathrm{v}$ & lei \\
\hline Production quantity & Stock & I & $q$ & units \\
\hline Bioplastics & Stock & I & bpv & lei \\
\hline Crop waste & Auxiliary & I & cwq & units \\
\hline Vegetable oils & Auxiliary & I & vog & units \\
\hline Starch & Auxiliary & I & $s q$ & units \\
\hline Vegetable fats & Auxiliary & I & $\mathrm{vfg}$ & units \\
\hline Turnover & Auxiliary & I & $t$ & lei * units \\
\hline Invested profit & Auxiliary & I & ip & lei * units \\
\hline Margin & Auxiliary & $\mathrm{O}$ & $\mathrm{m}$ & lei * units \\
\hline Plastics & Auxiliary & I & pv & lei \\
\hline Greenhouse foil & Auxiliary & I & gfv & lei \\
\hline Nets & Auxiliary & I & nv & lei \\
\hline Pipes & Auxiliary & I & ppv & lei \\
\hline Mulching & Auxiliary & I & $\mathrm{mv}$ & lei \\
\hline Direct covers & Auxiliary & I & dcv & lei \\
\hline Tunnels & Auxiliary & I & tv & lei \\
\hline Wrapping foil & Auxiliary & I & wfv & lei \\
\hline Human workforce & Auxiliary & 0 & hwv & lei \\
\hline Capital & Auxiliary & I & $\mathrm{cV}$ & lei \\
\hline Water & Auxiliary & I & wv & lei \\
\hline Fertilizers & Auxiliary & I & fv & lei \\
\hline Chemicals & Auxiliary & I & chv & lei \\
\hline Oils & Auxiliary & I & ov & lei \\
\hline Agrochemicals & Auxiliary & I & av & lei \\
\hline Seeds & Auxiliary & I & sv & lei \\
\hline TIME STEP & Model & 0 & - & - \\
\hline FINAL TIME & Model & $\mathrm{O}$ & - & year \\
\hline
\end{tabular}

Table 3

KEY VARIABLES TAKEN INTO CONSIDERATION 
-the calculation of the production value

$$
v=c * q
$$

-the calculation of the bioplastics dynamics

$$
b p v=\frac{i p}{s q+c w q+v f q+v o q}
$$

-the calculation of turnover

$$
t=m+v
$$

-the calculation of invested profit (considered that 10\% of the profit is invested in obtaining bioplastics)

$$
p=(t-v) \times 0.1
$$

3.The testing phase, which consist in the actual simulation of the behavior of the system variables. Usually, the output in this phase consist in the representation of the variable behavior as graph or table. For our model, the representation is shown in figure 1.

4.The implementation, which consist in applying the resulted conclusions as policies or principles within the real system.

Basically, the model is built using the SD principles and the parameters of the model are represented as stock and flow variables within the diagram.

\section{Results and discussions}

The graphical representation of the model presents the relations between the main variables taken into consideration and is presented in figure 1.

As we can clearly see in the graphical representation, the production cost is modeled regarding the components that form it, as shown in the literature. The plastics components used in agriculture, as shown in table 1, form a distinct component within the representation, in order to show their importance. The main development is the addition of the bioplastics within the plastic necessary, parallel with the reduction of costs given by the usage of bioplastics in the agriculture.

The representation shows the structural management of plastic materials used in agricultural processes. As a structural part of the final cost of production, these materials have the potential of cost reduction by easing parts of agricultural processes. The main disadvantage of these materials is the pollution referring to upper layers of soil, problem that can be solved by using different materials that can be biodegradable.

Coming back to the model, the cost with these materials can be found in the final production cost and, as an extension, in the final value of production. Figure 2 presents the causality trees for two variables, the value of the production and the bioplastics value. All the variables that precede the root (the main variable) influence its behavior, thus have a part of influence in obtaining the values of the roots. As we can see, the production value is influenced by the production cost, indirectly influenced by all the costs included in the final product cost. As for the bioplastics value, the main factors influencing the production of bioplastics being the raw material and the invested profit, either as direct investment for a mechanism of bioplastic production or as an outsourcing strategy.

Regarding the model simulation, we show a representation of the model behavior during a year in figure 3 , made using Vensim software [8]. As shown in the model, the production parameters fluctuate during the year, as well as the coverage of plastic material necessary. We can observe that the production cost has a natural trend, given the values for the parameters above.

Depending on the waste from the farm, the bioplastic value and, indirectly, the bioplastic production, have a fluctuating trend, due to the obtaining of the profit, the production cost and the production quantity (established as a minimum value for the crops).

Figure 4 shows the behavior in one year for four variables of the model in two scenarios: one with usage of plastics in agriculture (No plastics) and one with the usage of plastics in agriculture (Current).

As for the Production cost, we can observe that, at the beginning, the cost difference situates in average at 247.55 lei in favor of the Currentscenario, with obvious implications of the direct cost of plastics in the total production cost.

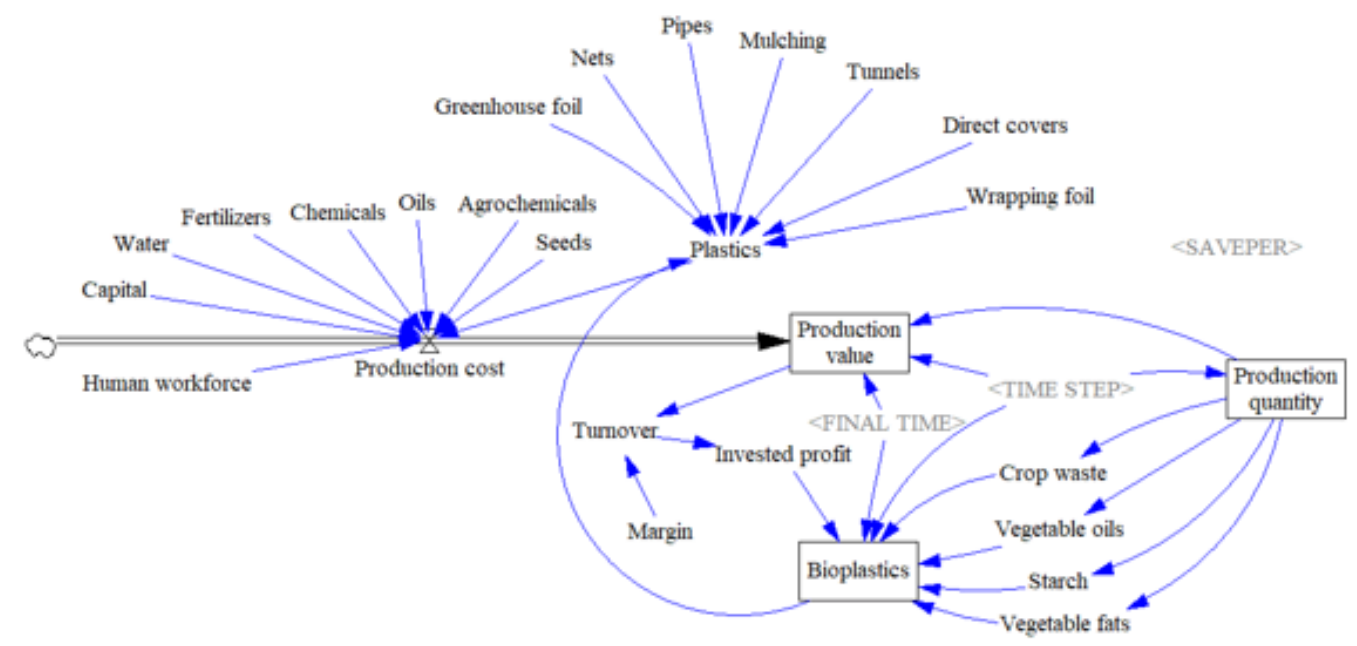

Fig. 1.Graphical representation of the model

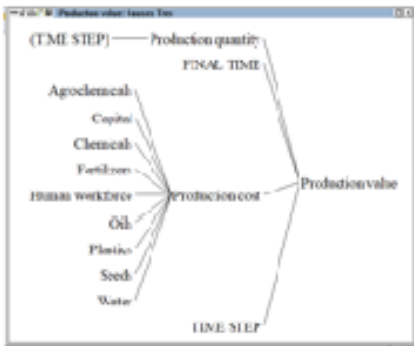

(a)

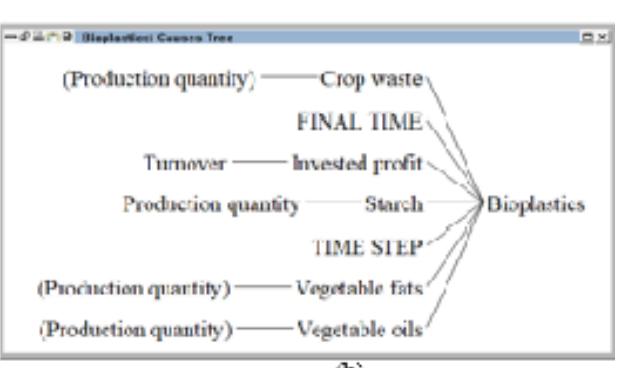

(b)
Fig. 2. Causality tree for production value (a) and bioplastics (b) 


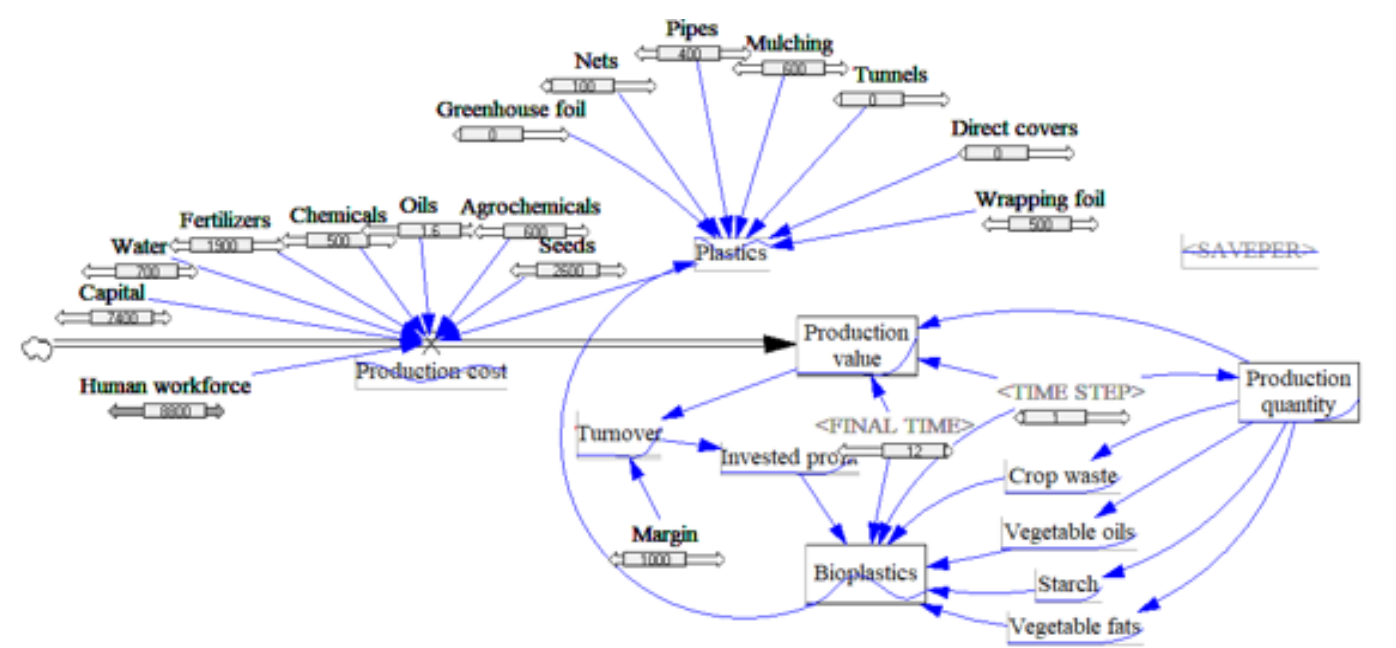

Fig. 3.Simulation of the model during a year

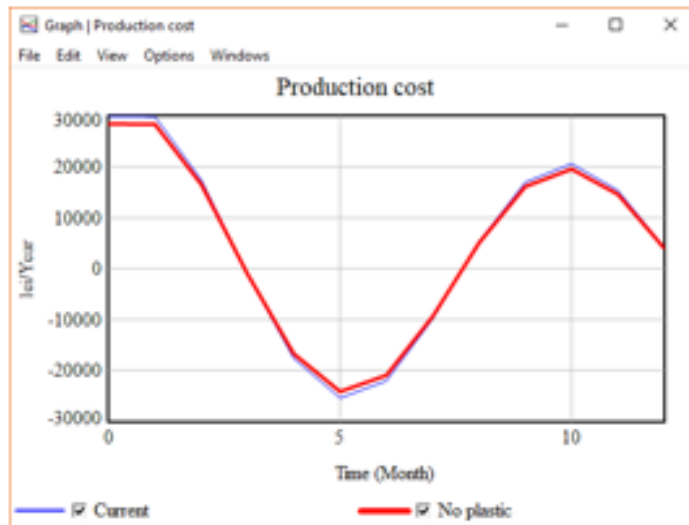

(a)

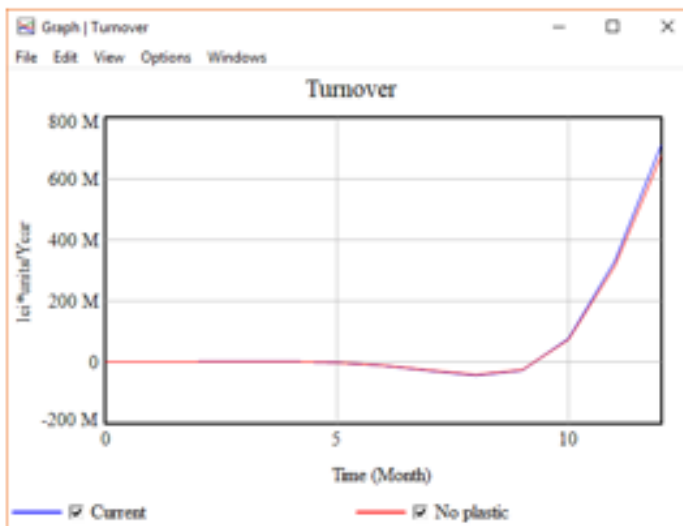

(c)

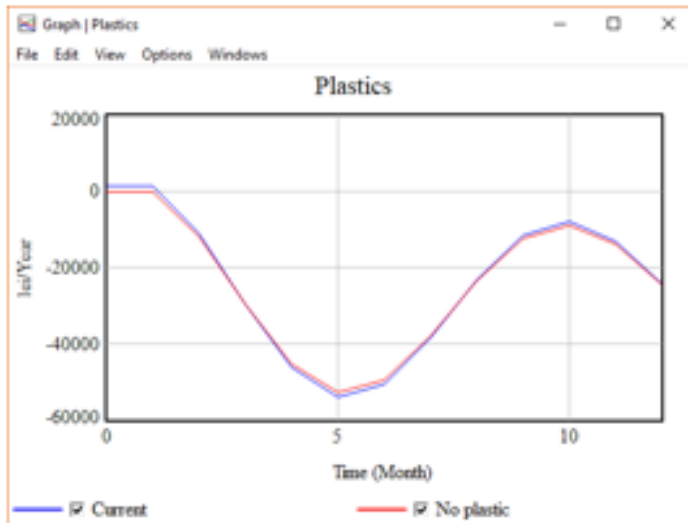

(b)

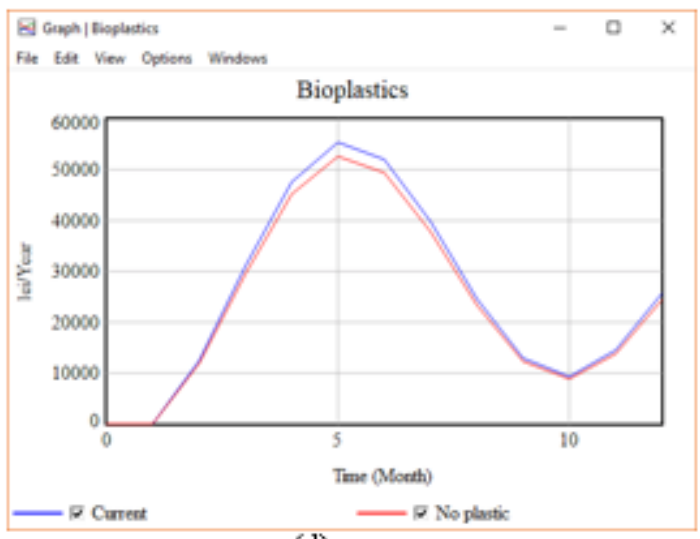

(d)
Fig. 4. Variable behavior in the two cases, with the usage of plastic (blue line) and without the plastic (red line) for production (a), plastics (b), turnover (c) and bioplastic value $(\mathrm{d})$
As for Plastics (as value), the consumption of plastic has an average difference between 53219.55 lei in favor of Current scenario, the main contribution of the negative values for the plastic cost being the addition and usage of the bioplastic value obtained within the enterprise.

Regarding the Turnover, the natural character of the agricultural domain is present in the part (c) of the figure. The turnover tends to have zero and negative values at the beginning, starting to grow as the crops are valued. Regarding the differences between the scenarios, the Current scenario has also higher values, due to the indirect cost with the plastic materials.

Bioplastics value (d) show a complementary behavior to plastics (b), due to the direct effect of cost reduction by obtaining bioplastic within the enterprise. The values are higher for the Current scenario, leading to the conclusion that the investment has a positive effect on the production of bioplastic.

As a final conclusion, the usage of plastic materials within the enterprise is a positive one, having the indirect effect of growing the economic indicators for profitability. A second conclusion leads to the investment in transforming natural waste from the agricultural processes into bioplastic, with direct effects on the enterprise profitability.

\section{Conclusions}

The model presented shows the obvious importance of the plastic materials within an agricultural enterprise. The second conclusion form the simulation of the model shows the importance of the usage of agricultural waste in order to obtain products useful in the enterprise with the direct effect on cost reduction and growth of optimality.

The built model and the simulation runs presented in this paper were made on a case study based on a cropbased agricultural enterprise. How ever, the waste produced in an agricultural enterprise also refers to materials resulted from livestock which can be used as a raw material for producing bioplastic. Future developments of the model would base on the extension for a livestock 
enterprise. Also, the development would be made for modeling the system using other methodologies, such as Business Process Modeling Notation (BPMN), based on representing processes within the enterprise, and models created in the Unified Model Language (UML). Also, a realistic model can be made using the methodologies used for model checking approaches.

\section{References}

1. R. BROWN, Polymers in Agriculture and Horticulture, iSmithers Rapra Publishing, 2004.

2. P. SINGH AND V. SHARMA, Integrated Plastic Waste Management: Environmental and Improved Health Approaches, Procedia Environmental Sciences, vol. 35, p. 692 - 700, 2016.

3. A. T. RAHOVEANU, M. T. RAHOVEANU AND T. DINU, Optimization of production structures in order to increase competitiveness of agricultural holdings, Economics of agriculture, vol. 58, no. 2, pp. 187193, 2011.
4.C. BAIER, J.-P. KATOEN, Principles of model checking, Cambridge, Massachusetts, London: The MIT Press, 2008.

5.S. ALBIN, Building a System Dynamics Model. Part 1: Conceptualization, Prepared for the MIT System Dynamics in Education Project Under the Supervision of Dr. J ay W. Forrester.

6.A. TUREK, Sustainable Agriculture: Between Sustainable Development and Economic Competitiveness, Sustainable Technologies, Policies, and Constraints in the Green Economy, pp. 219-235, 2013.

7.D. N. MOCUTA, The influence of climate change on sustainable development, Economic and Social Development: Book of Proceedings, Varazdin Development and Entrepreneurship Agency (VADEA), pp. 316-321, 2018.

8.*** Ventana Systems, Inc.. (2006). Vensim PLE Software, Ventana Systems Inc.. Retrieved at May 30, 2008, from the website temoa : Open Educational Resources (OER) Portal at http://www.temoa.info/ node/3682, [Online]

Manuscript received: 04.02.2019 